during the two years, as patients with the disease are generally treated in hospital and biological evidence of the disease is needed. This study provides a good representation of the patterns of the disease in France, with its autochthonous and imported cases.

In conclusion, kala-azar is present in the Mediterranean area, notably in southern France, and doctors must be aware of this, especially because, as our study showed, patients often present with not all of the classic clinical and biological features. Young children are especially at risk, and their disease is often not completely cured after a first course of pentavalent antimonial drugs. Studies on imported leishmaniasis are scarce, but, with the development of tourism and other forms of exchange with countries with a high endemicity of kala-azar, it would be useful for public health authorities to emphasise the risk of contamination, particularly in the Mediterranean area. ${ }^{17}$

We thank all the chiefs of hospital departments of parasitology, haematology, and biology, and their teams, who have kindly sent the data for this national survey. The study was supported by the National Department of Health, Office of Communicable Diseases, France.

1 World Health Organisation. Leishmaniasis. WHO Tech Rep Ser 1984; No 701. 2 Quilici $M$, Dunan S, Dumont $\mathrm{H}$, et al. Le kala-azar méditerranéen infantile dans le sud-est de la France. Ann Pediatr (Paris) 1987;34:369-73.

3 Hill FGH, Letsky E. Infantile kala-azar in Britain. BMF 1975;iii:334-5.
+ Wheatley T, Sacks S, Flemans RJ, Rubenstein D. Visceral leishmaniasis: a rare imported disease. I Infect 1983;7:166-7.

5 Kinmond S, Galea P, Simpson EM, Parida SK, Goel KM. Kala-azar in a Scottish child. Lancet 1989;ii:325.

6 Pugin P, Miescher PA. Le kala-azar, étude clinique et physiopathologique à propos d'un nouveau cas observé en Suisse. Schweiz Med Wochenschr 1968;93:1320-3.

7 Heilmann K, Dohnert G, Wohlenberg H. Todlich verlaufende leishmaniasis visceralis (kala-azar) bei Mittelmeerurlaubern. Dtsch Med Wochenschr 1971;96:36-8.

8 Ogunkolade BW, Vouldoukis I, Frommel D, Davoust B, Rhodes-Feuillette $A$, Monjour L. Immunisation of dogs with Leishmania infantum-derived vaccine. Vet Parasitol 1988:28:33-41.

9 Killick-Kendrick R, Rioux JA, Bailly M, et al. Ecology of leishmaniasis in the south of France. II Dispersal of Phlebotomus arisasy Tonnoir 1921 as a factor of the spread of visceral leishmaniasis in the Cevennes. Ann Parasitol Hum Comp 1984;59:555-72.

10 Montalban C, Sevilla F, Moreno A, et al. Visceral leishmaniasis: an opportunistic infection in AIDS. F Infect 1987;15:247-50.

11 Rocha H. Leishmania species. In: Mandell G, Douglas RG, Bennett JE, eds. Principles and practice of infectious diseases. New York: Wiley Medical Publication, 1979:2210-8.

12 Bryceson AD, Chulay JD, Mugambi $M$, et al. Visceral leishmaniasis unresponsive to antimonial drugs. II Response to high dosage sodium stibogluconate or prolonged treatment with pentamidine. Trans $R$ Soc Trop Med Hyg 1985;79:705-14.

13 Neva FA. Immunotherapy for parasitic disease. $N$ Engl f Med 1990;322:55-7. 4 Badaro R, Falcoff E, Badaro FS, et al. Treatment of visceral leishmaniasis with pentavalent antimony and interferon gamma. $N$ Engl $f$ Med 1990;322:16-21.

15 Anonymous. Situation du SIDA en France au 31 décembre 1986 [editorial]. Bulletin Epidemiologique Hebdomadaire 1987;7:3-4.

16 Office of Communicable Diseases. Paris: National Department of Health December 1987. (Unpublished.)

17 Jeannel D, Tuppin Ph, Brucker G, Danis M, Gentilini M. Leishmaniasis in France. Lancet 1989;ii:804.

(Accepted 24 May 1991)
Department of

Forensic

Psychiatry, Institute

of Psychiatry,

London

SE5 8AF

John Gunn, FRCPSYCH, professor of forensic psychiatry

Anthony Maden,

MRCPSYCH,

research worker

Mark Swinton,

MRCPSYCH,

research worker

Correspondence to:

Dr Maden.

BMF 1991;303:338-41

\title{
Treatment needs of prisoners with psychiatric disorders
}

\author{
John Gunn, Anthony Maden, Mark Swinton
}

\section{Abstract}

Objective-To describe the prevalence of psychiatric disorder and the treatment needs of sentenced prisoners in England and Wales.

Design-Population survey based on a $5 \%$ sample of men serving prison sentences.

Setting-Sixteen prisons for adult males and nine institutions for male young offenders representative of all prisons in prison type, security levels, and length of sentences.

Subjects -406 young offenders and 1478 adult men, 404 and 1365 of whom agreed to be interviewed.

Main outcome measures-History of psychiatric disorder, clinical diagnosis of psychiatrist, and required treatment.

Results-652 (37\%) men had psychiatric disorders diagnosed, of whom $15(0 \cdot 8 \%)$ had organic disorders, $34(2 \%)$ psychosis, $105(6 \%)$ neurosis, $177(10 \%)$ personality disorder, and $407(23 \%)$ substance misuse. $52(3 \%)$ were judged to require transfer to hospital for psychiatric treatment, $96(5 \%)$ required treatment in a therapeutic community setting, and a further $176(10 \%)$ required further psychiatric assessment or treatment within prison.

Conclusions-By extrapolation the sentenced prison population includes over 700 men with psychosis, and around 1100 who would warrant transfer to hospital for psychiatric treatment. Provision of secure treatment facilities, particularly long term medium secure units, needs to be improved. Services for people with personality, sexual, and substance misuse disorders should be developed in both prisons and the health service.

\section{Introduction}

Staff in our department surveyed sentenced men in the south east prison region in 1972 and found that
$31 \%$ had psychiatric disorders, $2 \%$ of whom were psychotic. ' The survey's results have been quoted as indicating that a third of all prisoners should be in psychiatric hospitals, ${ }^{2}$ but this is not what was found. The survey did not examine the question of treatment in detail, although some men were receiving treatment in prison and many more were reported to be suitable for such treatment, given adequate facilities.

We present the results of a further study that assessed psychiatric need in a 5\% sample of the male sentenced population, which in June 1988 consisted of 28602 men and 8141 male young offenders (aged 17-21 years). ${ }^{3}$ Assessment of cases was expanded to include decisions on appropriate treatment. No standard criteria exist for assessing treatment needs, so needs were decided on clinical grounds for each case; the process was similar to that used to decide on treatment in clinical practice.

\section{Methods}

Sentenced prisoners are held in over 120 institutions, comprising local, training, and open prisons. Institutions are further subdivided according to sentence length and level of security. Sampling all prisons was impractical so we selected 16 prisons containing adult men and nine containing male young offenders. Sampling within each prison was random, and varied from one in two to one in eight prisoners. We had information on the sentence length of inmates of all prisons and on the prison regimens. We selected prisons and sampling rates so that the sample was representative of the total prison population in terms of length of sentence and type of prison.

All inmates chosen were invited to be interviewed, being informed that the survey was confidential and conducted by doctors from outside the prison, that participation was voluntary, and that no individuals would be identified. Interviews were conducted during 
April 1988 to July 1989. We combined male adults and young offenders for analysis, as both were $5 \%$ samples of their respective populations.

\section{INTERVIEW AND DATA COLLECTION}

Each inmate's prison file was studied before the interview to obtain demographic and criminological information, reports of behaviour within prison, and social inquiry reports. The prisoner was then interviewed by a psychiatrist (AM or MS), in private within the prison. The semistructured interview was designed for the project and piloted on 50 volunteer prisoners; items with inter-rater reliability less than $90 \%$ were discarded. Prisoners were asked about past and present medical and psychiatric problems, substance misuse, and self harm. The clinical interview schedule provided a standardised assessment of mental state. ${ }^{4}$ The interview could be completed in 30 minutes for subjects without evidence of psychiatric problems, and was expanded as necessary for others. Further information was obtained from the inmate's prison medical record and from NHS hospitals if previous treatment was reported.

Subjects with significant disease had their condition diagnosed on the basis of their present state, according to the ICD code (ninth revision). ${ }^{5}$ Questions about substance misuse referred to the six months preceding the index offence. Each individual could have up to three conditions diagnosed.

Every inmate in whom psychiatric disorder was diagnosed was allocated to one of five categories of recommended treatment options:

None-This applied to prisoners with no mental disorder and to those with a disorder who did not want treatment, unless they required involuntary treatment under the Mental Health Act 1983.

Treatment within prison is treatment that a general practitioner or psychiatrist would provide on a mainly outpatient basis-for example, supportive psychotherapy or drugs, or both.

Therapeutic community refers to the type of contract based regimen under which people with personality disorders are treated at Grendon prison and Henderson Hospital and some drug and alcohol rehabilitation centres. No judgment had to be made about whether treatment should be provided in or out of prison, but the prisoner had to recognise he had a problem, be motivated to do something about it, and be capable of entering into a therapeutic contract.

Further assessment was used when there was uncertainty about the diagnosis, treatment, or motivation. We assumed that at least the initial stages of assessment would take place in prison. The outcome of assessment could range from no treatment to transfer to hospital. This category was used only when there was a high degree of suspicion that mental disorder was present.

Hospital meant that the prisoner required inpatient treatment outside the prison system. It included all prisoners needing involuntary treatment under the Mental Health Act 1983 and all inmates willing to accept treatment voluntarily but with a psychiatric disorder that could not be managed adequately and safely in prison.

Recommended treatments were decided on clinical grounds. In many cases the decision was taken by the interviewers, but in all cases of psychosis, in cases where a recommendation for hospital transfer was likely, and in all cases where the interviewers were in doubt about appropriate management, the case was referred to a meeting of the research panel. This consisted of psychiatrists, psychologists, and a social worker, all of whom worked in clinical forensic psychiatry. The panel met monthly, and cases were presented to it as if to a clinical case conference. The panel was asked to select the most appropriate of the five treatment options, and to estimate the level of security required for all prisoners recommended for hospital treatment, again using clinical criteria. The three categories were low security (district psychiatric service); intermediate security (regional secure unit); and maximum security (special hospital).

A list of the prisons visited and copies of the data collection sheet and coding manual can be obtained from us and will be included in a forthcoming report. ${ }^{\circ}$

\section{Results}

We randomly selected 1478 sentenced men and 406 young offenders for interview: $113 \mathrm{men}(7 \cdot 5 \%)$ and two young offenders $(0.5 \%)$ refused to participate. The characteristics of the sampled population were similar to those of the total prison population (table I). Comparisons are not shown for young offenders but the results were similar to those in adults.

Psychiatric conditions were diagnosed in 652 men (table II). Of the 34 psychotic prisoners, 22 were recognised as mentally disordered by the prison authorities (including 18 of the 21 with schizophrenia) and 27 reported treatment for psychiatric problems during their stay in prison.

Table III shows the recommended treatment for all prisoners according to the primary diagnoses. Fifty two men $(2 \cdot 9 \%, 95 \%$ confidence interval for the population $2 \cdot 1 \%$ to $3 \cdot 7 \%$ ) were judged to require transfer to hospital. Of the 30 psychotic prisoners recommended for hospital treatment, 21 had schizophrenia, six affective disorder, and three paranoid psychosis; hospital treatment was recommended for three prisoners with organic disorders; two with mild mental handicap and one with a frontal lobe syndrome. Seventeen inmates with schizophrenia and judged by

TABLE I-Comparison of characteristics in sample and total population of sentenced adult male prisoners

\begin{tabular}{lcc}
\hline Variable & $\begin{array}{c}\text { \% Of total } \\
\text { prison } \\
\text { population }\end{array}$ & $\begin{array}{c}\% \text { (No) of } \\
\text { sample }\end{array}$ \\
\hline Length of sentence: & & \\
$\quad$ Short (<18 months) & 27 & $27(367)$ \\
Medium (18-47 months) & 37 & $37(503)$ \\
$\quad$ Long ( $\geqslant 4$ years) & 36 & $36(495)$ \\
Type of prison: & 34 & \\
Local & 55 & $33(455)$ \\
Training & 11 & $12(750)$ \\
Open & 24 & $22(305)$ \\
Current offence: & 9 & $9(123)$ \\
Violence & 18 & $21(281)$ \\
Sexual & 10 & $14(190)$ \\
Burglary & 15 & $18(251)$ \\
Robbery & 10 & $10(129)$ \\
Theft & & $7(95)$ \\
Drugs & 8 & $16(225)$ \\
Other data: & 15 & \\
$\quad$ On rule 43 & &
\end{tabular}

TABLE II-Prevalence of psychiatric disorder in 1769 sentenced prisoners ${ }^{\star}$

\begin{tabular}{|c|c|}
\hline Diagnosis & No $(\%)$ of prisoners \\
\hline Psychoses: & $34(1.9)$ \\
\hline Schizophrenia & $21(1 \cdot 2)$ \\
\hline Affective & $7(0 \cdot 4)$ \\
\hline Paranoid & $6(0 \cdot 3)$ \\
\hline Neuroses: & $105(59)$ \\
\hline Neurotic disorders & $71(4)$ \\
\hline Adjustment reaction & $34(1 \cdot 9)$ \\
\hline Personality disorders & $177(10)$ \\
\hline Sexual deviations & $38(2 \cdot 1)$ \\
\hline Substance misuse & $407(23)$ \\
\hline Alcohol & $203(11.5)$ \\
\hline Drugs & $204(11 \cdot 5)$ \\
\hline Organic disorders: & $15(0.8)$ \\
\hline Epilepsy & $8(0.5)$ \\
\hline Mental retardation & $7(0 \cdot 4)$ \\
\hline Diagnosis uncertain & $18(1 \cdot 0)$ \\
\hline No diagnosis & $1117(63)$ \\
\hline
\end{tabular}


Recommended management

\begin{tabular}{|c|c|c|c|c|c|c|}
\hline Diagnosis & None & Prison care & $\begin{array}{c}\text { Further } \\
\text { assessment }\end{array}$ & $\begin{array}{l}\text { Therapeutic } \\
\text { community }\end{array}$ & Hospital & $\begin{array}{c}\text { Total No }(\%) \\
\text { prisoners }\end{array}$ \\
\hline Psychoses & & 4 & & & 30 & $34(2)$ \\
\hline Neurotic disorder & 9 & 72 & 1 & 3 & 4 & $89(5)$ \\
\hline Personality disorder & 38 & 31 & 31 & 39 & 6 & $145(8)$ \\
\hline Sexual disorder & 4 & 6 & 6 & 9 & 9 & $34(2)$ \\
\hline Substance misuse & 183 & 59 & 31 & 43 & & $316(18)$ \\
\hline Organic disorders & 4 & 2 & 3 & 2 & 3 & $14(1)$ \\
\hline Diagnosis uncertain & & 2 & 18 & & & $20(1)$ \\
\hline No diagnosis & 1117 & & & & & $1117(63)$ \\
\hline Total No $(\%)$ of prisoners & $1355(77)$ & $176(10)$ & $90(5)$ & $96(5)$ & $52(3)$ & $1769(100)$ \\
\hline
\end{tabular}

the research panel to require transfer had been identified by the prison doctor as psychotic, including eight who had been referred for transfer and were awaiting assessment or a bed.

Twelve of the 37 inmates recommended for hospital treatment for mental illness or organic disorder had developed their illness after imprisonment; the 25 others had been ill at the time of their offence, 24 of whom were known to their local psychiatric service. Psychiatric evidence had not been considered in the trials of seven of these inmates, and the remaining 18 were judged unsuitable for the treatment facilities available in hospitals, usually because of difficult or violent behaviour. Among prisoners with personality disorder and sexual deviation, the main reasons for failure to reach hospital were disagreements among doctors over treatability and lack of suitable facilities.

Seventeen prisoners were thought to require treatment in special hospitals, 21 in regional secure units, and 14 in district psychiatric service facilities.

\section{Discussion}

Our finding that $37 \%$ of sentenced prisoners had a psychiatric disorder, including $2 \%$ with psychosis, resembles closely the results of the 1972 survey. ${ }^{1}$ The overall pattern, with a high level of disorder but a low level of psychosis, agrees with other studies of sentenced prisoners. ${ }^{7-9}$

We found personality disorder in $10 \%$ of prisoners, which is comparable with the $13 \%{ }^{7}$ and $8 \%^{8}$ found in other prison surveys using clinical criteria, although it is considerably lower than the $22 \%$ found in $1972 .^{\prime}$ The most likely explanation for the differences is the low reliability of clinical criteria. All these figures are lower than those from American studies using standardised tools for assessment - for example, Guze labelled $78 \%$ of his sample "sociopathic." 10 We used clinical criteria to ensure relevance to psychiatric practice. The cases we identified represent the more severe end of the spectrum of personality disorder, and $74 \%$ of men in this category were judged in need of psychiatric treatment (table III). The fact that almost $12 \%$ of men had alcoholism diagnosed was not surprising but drug addiction is now equally common."

The prevalence of psychosis in prisons is comparable with that in the community, but this should not obscure its importance. The treatment options available to psychotic prisoners are limited, and the research panel judged that 30 of 34 psychotic prisoners could receive adequate psychiatric care only by being transferred to a NHS hospital. Reasons for recommending hospital transfer included unpredictable violence, life threatening self harm, victimisation by other prisoners, and a refusal to take prescribed drugs (drugs cannot be given compulsorily in prison, even to inmates who meet the criteria in the Mental Health Act 1983). In many cases, the opinion of the research panel was shared by other doctors treating the prisoner.
Two per cent of the sentenced prison population represents a large number of psychotic inmates: roughly 730 men at any one time, about 450 of whom would have schizophrenia. Similarly, by extrapolation about 1100 (95\% confidence interval 776 to 1405$)$ prisoners require hospital treatment for psychiatric disorders. The largest proportion of inmates requiring hospital treatment were judged to need medium security facilities. There are currently 600 medium security beds, considerably less than the 2000 recommended by Butler ${ }^{12}$ and the 1000 accepted as an initial target by the Department of Health and Social Security..$^{13}$

The problems presented by difficult patients are not new, ${ }^{14}$ and hospitals are particularly likely to reject convicted criminals with chronic conditions who have little prospect of recovery. ${ }^{15} 16$ Many of the patients we identified fell into this category. More facilities for long term care in conditions of medium security are needed. For prisoners who are accepted by the health service, a study at one special hospital showed that, between 1960 and 1983, the delay between medical recommendation and admission increased sevenfold, mainly because of shortage of beds. ${ }^{17}$ Prison doctors often complained of delays in the NHS response to requests for assessment. Proposed changes in the NHS may exacerbate this problem as they contain financial disincentives for health districts to take on chronic, difficult patients. The NHS reforms fail to address the question who will pay for the treatment of such patients in the future. ${ }^{18}$ Similar anxieties have been expressed about the funding of care for other "expensive" patient groups $^{19}$; regional funding has been suggested but the issue remains unresolved

For offenders with sexual deviation or personality disorder, provision of services outside prisons is rudimentary. Despite enormous public concern and the increasing numbers of violent and sex offenders accumulating in prisons ${ }^{3}$ psychiatry has failed to provide for these groups. Our figures show considerable unmet need and suggest that expansion of treatment facilities in both prisons and the health service should be a priority.

The treatment needs of many inmates could be met within the prison system. Approximately $6 \%$ of men were judged to require treatment in a therapeutic community setting for personality disorders, substance misuse, or sexual disorder. This is available at Grendon prison and the Wormwood Scrubs Annexe but the number of places is limited. Previous work ${ }^{1}$ has shown the effectiveness of Grendon prison ${ }^{120}$ and we believe another prison of this type should be developed. Provision for patients with such disorders has always been limited. Hospitals, especially hospitals with security, also need to develop treatment programmes for patients with personality disorders. Specialised assessment and treatment units for sex offenders would be valuable within both prisons and the NHS.

We studied only sentenced prisoners, excluding those on remand or who had defaulted on fines. The average daily prison population in England and Wales during 1988 was around 50000 and included 12000 remand prisoners, a group that is subject to the worst overcrowding and contains many people who have been remanded because of mental abnormality. Surveys of remand prisons show high levels of psychiatric illness ${ }^{21}$ and prison suicides are more common in this group. ${ }^{22}$ These prisoners add to the demands on psychiatric services in prisons.

This research was commissioned by the directorate of the Prison Medical Service and funded by the Home Office. The views expressed are those of the authors. We thank $\mathrm{Dr}$ Graham Robertson for help throughout the study. 
1 Gunn J, Robertson (i, Dell S, Way C. Psychiatric aspects of imprisonment. London: Academic Press, 1978

2 Weller MP. Mental illness - who cares? Nature 1989;339:249-52.

3 Home Office. Prison statistics England and W'ales 1988. London: HMSO, 1989 4 Goldberg DP, Cooper B, Eastwood MR, Kedward HB, Shepherd M. A standardised psychiatric interview for use in community surveys. British fournal of Preventive and Social Medicine 1970;24:18-23.

5 World Health Organisation. Mental disorders: glossary and guide to their classification in accordance with the ninth revision of the International Classitication of Diseases. Geneva: WHO, 1978.

6 Home Office. Mentally disordered prisoners. London: HMSO (in press)

7 Bluglass R. A psychiatric study of Scottish convicted prisoners. [MD thesis]. Edinburgh: Universiry of St Andrews, 1966.

8 Roper W'F. A comparative study of the Wakefield prison population in 1948. I British Journal of Delinquency 1950;1:15-28.

9 Roper WF. A comparative study of the Wakefield Prison population in 1948 II. British foumal of Delinquency 1950;1:243-70.

10 Guze SB. Criminality and psychiatric disorders. New York: Oxford University Pres, 1976.

11 Maden A, Swinton M, Gunn J. Drug dependence in prisoners. BMJ $1991 ; 302: 880$

12 Interim report of the committee on mentally abnormal offenders. HMSO, London: 1974. (Cmnd 5698.)
13 Department of Health and Social Security. Health service circular (interm series). London: DHSS, 1974. HSC(IS)61.

14 Secure accommodation in psychiatric hospitals. Lancet 1986;ii:24-5.

5 Cheadle J, Ditchfield J. Sentenced mentally ill offenders. London: Home Office Research and Planning Unit, 1982.

6 Coid J. Mentally abnormal prisoners on remand. 1. Rejected or accepted by the NHS. BMY 1988;296:1779-82.

17 Grounds A. The transfer of sentenced prisoners to hospital 1960-1983. British fournal of Criminology 1991:31:54-71.

18 Secretary of State for Health, Wales, Northern Ireland, and Scotland. Workin for patients. London: HMSO, 1990. (Cmnd 555.

19 Bentley C, Adler MW. Choice cuts for patients with Aids? BMf 1990;301: $501-2$.

20 Genders $\mathrm{E}$ Player $\mathrm{E}$ Grendon: a study of a therapeutic community within the prison system. Oxford: University of Oxford, Centre for Criminological prison system.

21 Taylor PJ, Gunn J. Violence and pswchosis. I. Risk of violence among psychotic men. BMF 1984;288:1945-9.

22 Dooley E. Prison suicide in England and Wales, 1972-87. Br f Psychiatr 1990;156:40-5.

Accepted 4 fune 1991
Abstract

Objective-To determine whether patients with condylomata acuminata have an increased risk of developing cancer.

Design-Prospective cohort study on patients diagnosed as having condylomata acuminata. The number of malignant tumours in the cohort was compared with national incidences obtained from the Swedish Cancer Registry.

Setting-Dermatology department of the Karolinska Hospital, Stockholm, Sweden.

Subjects -3260 patients (2549 males and 711 females, median (range) age 23 (1-80) years) seen during $1969-84$, with a mean follow up of 7.8 years.

Main outcome measures-Number of malignant tumours observed in the cohort during the study period and expected number from national incidence.

Results - There were 27 malignancies in the study group. There was no significant increase genital cancer in females compared with the national incidence. Only one patient had invasive cervical cancer (relative risk $=1 \cdot 8 ; 95 \%$ confidence interval 0 to $10 \cdot 1)$. Seventeen women had cervical carcinoma in situ $(1.5 ; 0.9$ to 2.5$)$ compared with an expected number of $11 \cdot 5$; this increase was not significant. For males 22 cancers were observed at all sites $(1 \cdot 6 ; 1 \cdot 0$ to $2 \cdot 5)$. The number of genitourinary cancers observed in males was almost three times higher than expected $(2 \cdot 6 ; 1 \cdot 2$ to $5 \cdot 0)$.

Conclusion-The results indicate that the risk of developing cervical carcinoma in situ or invasive cervical cancer after a genital human papillomavirus infection is less than previously thought. The implications of increase in the genitourinary malignancies in males are uncertain.

\section{Introduction}

Condylomata acuminata and cancer are ancient diseases. ${ }^{1}$ The first descriptions of condyloma were given by ancient Roman physicians. ${ }^{2}$ It was realised early on that condyloma was a venereal disease, and it has been connected with syphilis and, later, homosexuality. ${ }^{3}$ It was not until 1954 that the true nature of transmission was elucidated. American soldiers in Korea developed condyloma after having sexual intercourse with indigenous women. Four to six weeks after their homecoming their wives developed condyloma. The viral aetiology was established in 1968, when viral particles were identified in genital warts, ${ }^{5}$ and 10 years ago it was found that the particles were strains of human papillomavirus other than the strain that causes verruca vulgaris. ${ }^{6}$ Today more than 60 types of the virus are known, some of which have several subtypes. ${ }^{7}$ The clinical importance of some of these types is not clear. Human papillomavirus types 6 and 11 are associated with benign condylomatous lesions and low grade cervical intraepithelial neoplasia, and human papillomavirus types 16 and 18 are associated with cervical intraepithelial neoplasia and invasive cancer.

The association between genitoanal human papillomavirus infection and cancer is not new. There are several reports of patients with coexistence of condyloma and malignant neoplasm or cervical intraepithelial neoplasia. ${ }^{8-11}$ Human papillomavirus structural proteins have been found in patients with cervical intraepithelial neoplasia. ${ }^{1213}$ DNA hybridisation has shown human papillomavirus types 16 and 18 DNA sequences in lesions of invasive cervical cancer, integrated in the genome of the malignant cells. ${ }^{14}$

Although it is now becoming increasingly accepted that some human papillomavirus types are involved in the induction of genital cancers there is no clear epidemiological evidence that they cause cancer. ${ }^{15} \mathrm{We}$ know of only one large prospective study on the development of malignancy in patients with condyloma ${ }^{1617}$ though numerous papers report the recent increase in the incidence of condylomata acuminata..$^{16}$ is In this study we investigated the development of genital cancer in a large group of patients with condyloma.

\section{Patients and methods}

Patients-During 1969-84, 3260 patients with condylomata acuminata were seen at the dermatology department of our hospital. We examined the patients records and recorded the year of diagnosis, age, and sex. The records of patients seen during 1974 and 1975 were not available. The patient population consisted of 2549 males and 711 females (fig 1), with a median (range) age at diagnosis of 23 (1-80) years. The mean follow up period was $7 \cdot 8$ years. The number of person 